\title{
DAMPAK PENDIDIKAN KRISTEN BAGI ANAK \\ THE IMPACT OF CHRISTIAN EDUCATION ON CHILDREAN
}

Oleh :

\author{
TITANIA MODINGGE \\ Institut Agama Kristen Negeri Toraja \\ taniamodinge@gmail.com
}

\begin{abstract}
Every Christian, especially children, really need criteria to test the truth, views, and understandings that develop in the midst of context. Christians believe that God is the source of truth and has revealed His truth in and through the word and person of Christians. Therefore, the philosophical formulation of Christians who contemplate various aspects of life cannot be separated from the framework of the Bible's thought as God's written revelation.
\end{abstract}

Christian education for children as part of the spiritual sciences in empirical science is called to be able to test certainty, truth, views, and understandings that develop in the context of a society that has been influenced by modern science that has developed apart from the word of God. Christians as educators for children must hold that God is the source of truth and has revealed His truth in the Word and the Christian person. The Bible should be a source of education for children.

KEYWORDS : education, children, bible, truth, views, understanding

\section{ABSTRAK}

Setiap orang kristen terlebih anak-anak sangat membutuhkan kriteria untuk menguji kebenaran,pandangan, dan pemahaman yang berkembang ditengah konteks. Orang kristen percaya bahwa Allah adalah sumber kebenaran dan telah menyatakan kebenaranNya tersebut dalam dan melalui firman dan pribadi orang kristen. Karena itu rumusan falsafah orang kristen yang merenungkan berbagai segi kehidupan tidak lepas 
dari kerangkah pemikiran Alkitab sebagai penyataan tertulis Allah.

Pendidikan kristen bagi anak sebagai bagian dari ilmu-ilmu rohani dalam ilmu empirik terpanggil untuk dapat menguji kepastian,kebenaran,pandangan, dan pemahaman yang berkembang ditengah konteks masyarakat yang telah dipengaruhi oleh ilmu pengetahuan modern yang berkembang lepas dari firman Allah. Orang kristen sebagai pelaku pendidikan kepada Anak harus berpegang bahwa Allah adalah sumber kebenaran dan telah menyatakan kebenaranNya itu dalam Firman dan pribadi orang kristen. Alkitab harus menjadi sumber pendidikan bagi anak.

KATA KUNCl : pendidikan, anak-anak, Alkitab, kebenaran, pandangan, pemahaman

\section{PENDAHULUAN}

Istilah pendidikan kristen berasal dari bahasa Inggris "Christian Education" yang berarti pendidikan yang berproses pada pribadi Tuhan Yesus dan Alkitab (Firman Allah) sebagai dasar dan sumber acuannya. ${ }^{7}$ Arti pendidikan Kristen sebenarnya ialah bahwa dengan menerima pendidikan itu maka anak-anak memasuki persekutuan iman yang hidup dengan Tuhan sendiri dan oleh dalam Dia mereka berhisap pula pada persekutuan jemaat-Nya yang mengakui dan mempermuliakan nama-Nya disegala waktu dan tempat ${ }^{2}$. Oleh karena itu pendidikan kristen bagi anak-anak sangat penting karena pendidikan kristen meletakan dasar pengajarannya pada pengajaran dan tindakan Yesus Kristus.

\section{PEMBAHASAN}

Anak-anak adalah individu yang unik yang mempunyai eksistensi yang memiliki jiwa sendiri serta mempunyai hak untuk tumbuh dan berkembang secara optimal sesuai dengan iramanya masing-masing yang khas ${ }^{3}$. Pendidikan merupakan turun-temurun yang sifatnya berlangsung terus- menerus dalam arti bahwa kepada anak-anakpun merupakan suatu keharusan demi kelanjutan generasi penerus.

\footnotetext{
${ }^{1}$ Paulus Lilik Kristianto, Prinsip dan Praktik Pendidikan Agama Kristen,(Yogyakarta: Andi, 2006), 4

${ }^{2}$ E.G.Homrighausen dan I.H. Enklaar, Pendidikan Agama Kristen,(Jakarta : Gunung Mulia,2009),26

${ }^{3}$ Elisabeth, Pembelajaran PAK pada Anak Usia Dini, (Bandung: Bina Media Informasi,2009) , 68
} 
Dengan amanat Tuhan Yesus adalah merupakan pengajaran rohani yang harus diwariskan kepada semua golongan termaksud anak-anak harus menerima warisan rohani, hal ini dapat dilihat dalam perhatian Yesus kepada anak- anak (Matius 18:10,14 ; Markus 10:14, 16; Lukas 9:48). Penyataan kasih Allah dalam Yesus Kristus tidak hanya ditunjukan kepada orang dewasa, melainkan tugas kepada anak-anak.

Dalam hal ini anak- anak perlu perhatian yang akan mengarahkan dirinya untuk mengenal dan meningkatkan iman, seorang anak dibimbing pertama kalinya dalam lingkungan keluarga, yaitu orang tua, sebagai pengasuh yang utama dalam hidupnya. Anak -anak melihat bagaimana orang tuanya berperilaku selanjutnya meniru lanjut perilaku tersebut. Peniruan dalam tulisan ini , diberi makna positif pada peniruan sebagai salah satu proses belajar dalam totalitas kehidupan anak, baik disekolah, dirumah, dan dalam persekutuan di gereja, hingga interaksi sosialnya. Maka setiap orang tua harus selektif dalam memilih sekolah bagi anaknya dan harus selektif. ${ }^{4}$

Hidup anak-anak kristen harus berakar dalam persekutuan dengan gereja bahwa iman mereka harus dibangkitkan dengan mendengarkan injil, dan kehidupan mereka dibimbing oleh pekerjaan Roh Kudus. Itulah sebabnya pemahaman-pemahaman masa kini dalam penelaan Alkitan dan teologia Alkitabiah memperoleh tanggapan diantara bidang pendidikan kristen. Banyak orang yang mencari jalan agar penghayatan iman kristen yang telah bermakna dalam kehidupan orang-orang percaya sejak awal pertama gereja, dapat pula bermakna dalam kehidupan orang-orang yang terus bertumbuh. Mereka yakin bahwa Allah masih tetap berbicara melalui halaman-halaman Alkitab, dan mereka berharab bahwa la juga akan berbicara lewat Alkitab itu kepada Anak- anak pada saat ini. ${ }^{5}$

Pendidikan sekolah formal bukan jaminan bagi pendidikan iman ${ }^{6}$. Untuk memahami makna pendidikan kita harus melihatnya dalam wawasan lengkapnya Pada sisi lain, Alkitab menekankan betapa pentingnya disiplin yang penuh kasih. Orang tua

\footnotetext{
${ }^{4}$ Rannu Sirenden, "Exemplary Menemukenali Kunsi Pendidikan Bagi Anak Dalam Keluarga dan Pembelajaran Agama di Sekolah," Jurnal PAK_ Ganjil 3, no.1 (November 2021): 2, https://osf.io/bmtrk/ ${ }^{5}$ P.Siahaan Stephen Suleeman, Dinamika pendidikan Kristen (Jakarta : BPK Gunung Mulia,2006), xi ${ }^{6}$ Rannu Sirenden, "Exemplary Menemukenali Kunci Pendidikan Bagi Anak Dalam Keluarga Dan Pembelajaran Agama di Sekolah," Jurnal PAK_Ganjil 3, no.1 (November 2021) :1, https://osf.io/bmtrk/
} 
yang tidak menanamkan kedisiplinan terhadap anak, akan menghadapi akibat-akibat yang dapat menyakitkan dikemudian hari, baik pada diri orang tua maupun pada anak itu sendiri ${ }^{7}$. Untuk itu sangat penting untuk mengajaran pendidikan kristen dan mendisiplinkan anak dalam kedihupannya agar ia mengenal kasih Allah yang nyata dalam Tuhan Yesus Kristus. Sehingga dengan pimpinan roh kudus, anak datang ke dalam persekutuan dan hidup dalam Tuhan.

\section{TUJUAN DAN MANFAAT}

Dalam memahami tujuan pendidikan Kristen bagi anak-anak tidak terlepas dari tujuan pendidikan kristen secara keseluruhan dan tujuan pendidikan ini tentunya tidak akan terlepas dari tugas Gereja. Tujuannya itu meliputi : pengajaran, menjelaskan, melengkapi, menyanggupkan, mengarahkan dan membantu, setiap orang atau setiap anak bertumbuh dalam pengetahuan, sikap dan perbuatan. ${ }^{8}$

Jadi, suatu pelayanan yang benar bisa atau akan menciptakan hasil yang sangat baik. Dan anak-anak akan terbiasa dalam lingkungan yang penuh didikan rohani yang berdampak baik bagi mereka dan pertumbuhan mereka. Dengan didikan yang rohani seorang anak akan lebih mengenal dirinya, secara rohani dalam arti menyadari perbuatan yang dilakukannya, karena seorang anak sangat takut akan hukuman yang akan menimpa dirinya jika dia berbuat salah

Tujuan pendidikan kristen adalah untuk meningkatkan pendidikan iman anak. Agar anak memiliki iman yang baik dan benar kepada Allah. Sehingga orang tua sangat berperan dalam pendidikan ini, untuk membimbing dan mengarahkan anaknya untuk mengalami makna iman, agar anak memiliki iman yang baik dan benar kepada Allah.

\footnotetext{
${ }^{7}$ Rannu Sirenden, "Exemplart Menemukenali Kunci Pendidikan Bagi Anak dalam Keluarga dan Pembelajaran Agama di Sekolah" jurnal PAK_Ganjil 3, no.1 (November 2021) : 9, https://osf.io/bmtrk/

${ }^{8}$ Rida Gultom \& Dkk, Pendidikan Agama Kristen Kepada Anak-Anak, (Medan: CV. Mitra, 2011) ,10
} 


\section{KESIMPULAN DAN SARAN}

Dari materi diatas, dapat disimpulkan bahwa Pendidikan Kristen bagi anak merupakan suatu hal yang sangat penting karena berdampak berbagai aspek perkembangannya dan berpengaruh karakteristik, mental, bahkan kemampuan yang yang dapat berubah-ubah sesuai dengan lingkungan hidupnya. Pada usia tersebut bisa dikatakan masih dalam tahap yang labil, kebingungan dan jatih diri. Beberapa tahap atau metode pengajaran yang dilakukan untuk membimbing anak agar lebih baik terutama dalam iman dan kepercayaan terhadap Allah. Pendidikan ini dibuat untuk menglahirkan anak-anak yang lebih yang berbakti dan mempraktekan kebenarankebenaran yang sesuai dengan Alkitab. Karena sebagai orang Kristen diperlakukan pemahaman akan berbagai aspek yang mengarahkan orang-orang menuju nilai-nilai rohani yang terkandung dalam Alkitab.

Kemudian peran orang tua dan gereja dalam pendidikan dan perkembangan anak harus berpusat dari Firman Tuhan. Dalam hal ini keluarga dan gereja harus bekerja sama dalam menentukan dan mempertimbangankan moral dan perilaku anak dengan memanfaatkan perannya sebagai kesempanan emas memberikan nilai-nilai yang berharga bagi anak dan diperlukan strategi khusus dalam membentuk perilaku anak supaya memperoleh hasil yang maksimal yaitu perilaku positif anak.

\section{SARAN}

Pendidikan kristen kepada anak sebaiknya dilakukan denagan motode-metode yang bisa membantu proses pertumbuhan iman mereka dengan bermain pada anak(bisa bercerita,drama,diskusi,menyanyi,bermain terbimbing) dan metode-metode 
itu haruslah memahami anak-anak yang akan diajarkan. kemudian keluarga sebagai pendidik utama dalam pertumbuhan anak haruslah menjadi contoh yang baik dalam pertumbuhan iman dan karakter, serta mampu menjadi teladan yang baik bagi anakanaknya.

\section{DAFTAR PUSTAKA}

$\checkmark$ Sirenden Rannu. "Exemplary Menemukenali Kunci Pendidikan Bagi Anak Dalam Keluarga dan Pembelajaran agama di Sekolah," Jurnal PAK_ganjil 3, no.1 (November 2021):1-5

$\checkmark$ I.H. Enklaar \& E.G Homrighausen, Pandidikan Agama Kristen, Jakarta: BPK Gunung Mulia,2009

$\checkmark$ Puleeman Stephen Siahaan. P Dinamika Pendidikan Kristen. Jakarta : BPK Gunung Mulia, 2006

$\checkmark$ Elisabeth., Pembelajaran PAK Pada Anak Usia Dini, Bandung: Bina Media Informasi, 2009

$\checkmark$ Kristianto,Paulus Lilik, Prinsip dan Praktik Pendidikan Agama Kristen. Yogyakarta : Andi, 2006

$\checkmark$ Dkk \& Rida Gultom., Pendidikan Agama Kristen kepada Anak-Anak, Medan: CV. Mitra, 2011 